02 Royal Netherlands Institute for Sea Research

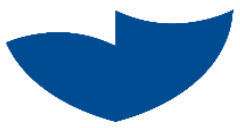

This is a pre-copyedited, author-produced version of an article accepted for publication, following peer review.

de Bar, M.W.; Weiss, G.M.; Yildiz, C.; Rampen, S.W.; Lattaud, J.; Bale, N.J.; Mienis, F.; Brummer, G.-J.A.; Schulz, H.; Rush, D.; Kim, J.-H.; Donner, B.; Knies, J.; Lückge, A.; Stuut, J.-B.; Sinninghe Damsté, J.S. \& Schouten, S. (2020). Global temperature calibration of the Long chain Diol Index in marine surface sediments. Marine Chemistry, 224, 103815

Published version: https://doi.org/10.1016/j.orggeochem.2020.103983

NIOZ Repository: http://imis.nioz.nl/imis. php?module=ref\&refid=323732

Research data: https://doi.pangaea.de/10.1594/PANGAEA.912140

[Article begins on next page]

The NIOZ Repository gives free access to the digital collection of the work of the Royal Netherlands Institute for Sea Research. This archive is managed according to the principles of the Open Access Movement, and the Open Archive Initiative. Each publication should be cited to its original source - please use the reference as presented.

When using parts of, or whole publications in your own work, permission from the author(s) or copyright holder(s) is always needed. 
3 Marijke W. de Bar ${ }^{\mathrm{a}, *}$, Gabriella Weiss ${ }^{\mathrm{a}, 1}$, Caglar Yildiz ${ }^{\mathrm{a}}$, Sebastiaan W. Rampen ${ }^{\mathrm{b}}$, Julie

4 Lattaud $^{\mathrm{a}, 2}$, Nicole J. Bale ${ }^{\mathrm{a}}$, Furu Mienis ${ }^{\mathrm{a}}$, Geert-Jan A. Brummer ${ }^{\mathrm{a}, \mathrm{c}}$, Hartmut Schulz ${ }^{\mathrm{d}}$, Darci

\section{Global temperature calibration of the Long chain Diol Index in marine surface sediments}

Rush $^{\mathrm{a}}$, Jung-Hyun Kime, Barbara Donner ${ }^{\mathrm{f}}$, Jochen Knies ${ }^{\mathrm{g}, \mathrm{h}}$, Andreas Lückge ${ }^{\mathrm{i}}$, Jan-Berend W.

Stuut $^{\mathrm{a}, \mathrm{c}}$, Jaap S. Sinninghe Damstéa,j and Stefan Schouten ${ }^{\mathrm{a}, \mathrm{j}, *}$

${ }^{a}$ NIOZ Royal Netherlands Institute for Sea Research, and Utrecht University, P.O. Box 59, 1790

AB Den Burg, Texel, the Netherlands

bUniversität Göttingen, Geoscience Center, Geobiology Group, Goldschmidtstrasse 3, 37073

Göttingen, Germany

${ }^{\mathrm{c}}$ Vrije Universiteit Amsterdam, Faculty of Science, Department of Earth Sciences, De Boelelaan 1085, 1081HV Amsterdam, the Netherlands

${ }^{\mathrm{d}}$ Universität Tübingen, Faculty of Science, Mikropaläontologie, Hölderlinstrasse 12, 72074

Tübingen, Germany

${ }^{\mathrm{e}}$ Korea Polar Research Institute (KOPRI), 26 Songdomirae-ro, Yeonsu-gu, Incheon 21990, South Korea

${ }^{\mathrm{f}}$ Universität Bremen, Center for Marine Environmental Sciences, Leobener Strasse, 28359

Bremen, Germany

${ }^{\mathrm{g}}$ Geological Survey of Norway (NGU), P.O. Box 6315, 7040 Trondheim, Norway

${ }^{\mathrm{h}}$ CAGE - Centre for Arctic Gas Hydrate, Environment and Climate; Department of Geosciences, UiT The Arctic University of Norway, 9037 Troms $\phi$, Norway

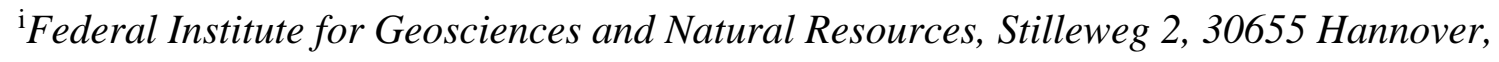


25 jUtrecht University, Faculty of Geosciences, Department of Earth Sciences, P.O. Box 80115, 263508 TC Utrecht, the Netherlands

27

$28 *$ Corresponding author: Marijke W. de Bar (marijkedebar@gmail.com) and Stefan Schouten

$29 \quad$ (s.schouten1@uu.nl)

$30 \quad{ }^{1}$ Present address: Pennsylvania State University, Jordan Road, 16563, University Park, PA, USA

$31 \quad 2$ Present address: ETH Zurich, Rämisstrasse 101, 8092 Zurich, Switzerland 32 


\section{ABSTRACT}

The Long chain Diol Index (LDI) is a relatively new organic geochemical proxy for sea surface temperature (SST), based on the abundance of the $\mathrm{C}_{30}$ 1,15-diol relative to the summed abundance of the $\mathrm{C}_{28}$ 1,13-, $\mathrm{C}_{30}$ 1,13- and $\mathrm{C}_{30}$ 1,15-diols. Here we substantially extend and reevaluate the initial core top calibration by combining the original dataset with 172 data points derived from previously published studies and 262 newly generated data points. In total, we considered 595 globally distributed surface sediments with an enhanced geographical coverage calibration but with considerably increased scatter. The effects of freshwater input (e.g., river runoff) and long-chain diol contribution from Proboscia diatoms on the LDI were evaluated. Exclusion of core-tops deposited at a salinity $<32 \mathrm{ppt}$, as well as core-tops with high Probosciaderived $\mathrm{C}_{28}$ 1,12-diol abundance, resulted in a substantial improvement of the relationship between LDI and annual mean SST. This implies that the LDI cannot be directly applied in regions with a strong freshwater influence or high $\mathrm{C}_{28}$ 1,12-diol abundance, limiting the applicability of the LDI. The final LDI calibration $\left(\mathrm{LDI}=0.0 .0325 \times \mathrm{SST}+0.1082 ; \mathrm{R}^{2}=0.88 ; n=\right.$ 514) is not statistically different from the original calibration of Rampen et al. (2012) (https://doi.org/10.1016/j.gca.2012.01.024), although with a larger calibration error of $3{ }^{\circ} \mathrm{C}$. This larger calibration error results from several regions where the LDI does not seem to have a strong 
temperature dependence with annual mean SST, posing a limitation on the application of the

$$
\text { LDI. }
$$

Keywords: LDI core-top calibration, long-chain diols, SST, freshwater, Proboscia diatoms

\section{Introduction}

The present-day release of anthropogenic greenhouse gases into the atmosphere has resulted in warming of the Earth's atmosphere and surface oceans, which is expected to continue in the coming decades (IPCC, 2014). However, the actual extent of this temperature rise and its implications for global climate is difficult to accurately predict due to the complexity of the Earth's climate system. For the prediction of future climate conditions, we typically rely on computer simulations of ocean-atmosphere circulation models, which in turn rely on time-series of observational data of various climate parameters. However, instrumental records only extend back to the last century. To accurately predict climate, it is essential to study natural climate evolution on geological timescales. For this purpose, a variety of climate proxies need to be used.

One of the most important climate parameters is past sea surface temperature (SST), since oceans make up more than two thirds of the world's surface, and therefore profoundly influence (and respond to) global climate. Proxies are commonly based on measurements of either inorganic or organic remnants of organisms preserved in sediment. One of the most commonly applied inorganic paleotemperature proxies uses the stable oxygen isotopic composition $\left(\delta^{18} \mathrm{O}\right)$ of the carbonate shells of foraminifera (e.g., Emiliani, 1955; Shackleton et al., 1967). Also, the $\mathrm{Mg} / \mathrm{Ca}$ ratio measured in a foraminiferal shell is correlated with temperature (e.g., Nürnberg et al., 1996). Organic temperature proxies, on the other hand, are generally based 
on lipid biomarkers, which are specific for a certain organism or a group of organisms. In paleoclimate studies there are two biomarker proxies for SST which are frequently applied. The first is the $U_{37}^{K \prime}$ index, based on long-chain unsaturated alkenones, detected in marine sediments world-wide, which uses the ratio of the di-unsaturated $\mathrm{C}_{37}$ methyl alkenones over the triunsaturated $\mathrm{C}_{37}$ methyl alkenones (Brassell et al., 1986; Prahl and Wakeham, 1987). This ratio is positively correlated with temperature, since the modern-day alkenone producers (mainly Emiliania huxleyi and Gephyrocapsa oceanica; e.g., Volkman et al., 1980, 1995; Marlowe et al., 1984; Conte et al., 1995) synthesize $\mathrm{C}_{37}$ alkenones, of which the degree of saturation varies with growth temperature (Brassell et al., 1986; Prahl and Wakeham, 1987). The temperature range of the proxy is between $-2{ }^{\circ} \mathrm{C}$ and ca. $29^{\circ} \mathrm{C}$ (Müller et al., 1998; Conte et al., 2006; Tierney and Tingley, 2018).

The second proxy, $\mathrm{TEX}_{86}$, is based on the distribution of isoprenoid glycerol dialkyl glycerol tetraethers (GDGTs), produced by the archaeal phylum Thaumarchaeota (see Schouten et al., 2013 for a review). These archaea synthesize GDGTs containing 0-3 cyclopentane moieties (GDGT-0 to GDGT-3) and crenarchaeol, which contains 4 cyclopentane rings and a cyclohexane moiety (Schouten et al., 2002; Sinninghe Damsté et al., 2002). The proxy is based on the relative abundance of GDGT-1, GDGT-2 and GDGT-3 and an isomer of crenarchaeol (Schouten et al., 2002). The index is positively correlated with annual mean SST, showing an increase in the number of cyclopentane moieties with increasing temperature, and can be applied, with caution, at temperatures $>30{ }^{\circ} \mathrm{C}$. All these proxies have advantages but also recognized uncertainties, and since these uncertainties are proxy-specific, SST reconstructions are ideally based on multiple proxies. Accordingly, the development of additional proxies is desired. 
Rampen et al. (2012) proposed the Long chain Diol Index (LDI), based on the fractional abundances of long-chain alkyl diols (LCDs), specifically the $\mathrm{C}_{28}$ and $\mathrm{C}_{30}$ 1,13-diols and $\mathrm{C}_{30}$ 1,15-diols, which contain a hydroxy group at $\mathrm{C}_{1}$ and a hydroxy group at the $\mathrm{C}_{13}$ or $\mathrm{C}_{15}$ position, respectively:

$$
\mathrm{LDI}=\left[\mathrm{C}_{30} \text { 1,15-diol }\right] /\left(\left[\mathrm{C}_{28} \text { 1,13-diol }+\mathrm{C}_{30} \text { 1,13-diol }+\mathrm{C}_{30} \text { 1,15-diol }\right]\right)
$$

The LDI, based on 161 globally distributed core-top sediments, shows a strong correlation with SST described by the following transfer function:

$$
\mathrm{LDI}=0.033 \times \mathrm{SST}+0.095 \quad\left(n=161 ; \mathrm{R}^{2}=0.97 ; \mathrm{RE}=2.0^{\circ} \mathrm{C}\right)
$$

The main limitation of the LDI is the fact that the producers of the 1,13-diols and 1,15diols in the ocean are still unknown. Cultured freshwater and marine eustigmatophyte algae produce 1,13-diols and 1,15-diols (Volkman et al., 1992; 1999; Gelin et al., 1997; Méjanelle et al., 2003; Shimokawara et al., 2010; Rampen et al., 2014b), but the LCD distributions observed in the cultures are dissimilar from the distributions observed in the marine environment. Moreover, these eustigmatophytes rarely occur in the ocean (e.g., Balzano et al., 2018). In contrast, Shimokawara et al. (2010) observed that the LCD distributions in the eustigmatophyte Nannochloropsis sp. (containing a dominant $\mathrm{C}_{32}$ 1,15-diol) were similar to that observed in sediments of Lake Baikal, suggesting that eustigmatophytes might produce LCDs in lakes. Additionally, Villanueva et al. (2014) observed similar trends for 18S rRNA gene copy numbers of (yet unknown) eustigmatophytes with LCD concentrations in an African lake, confirming eustigmatophytes as potential LCD producers in freshwater. However, Rampen et al. (2014b) tested the LDI in 62 lakes and found that the correlation with temperature was weak $\left(\mathrm{R}^{2}=0.33\right)$, which is likely because of the presence of different eustigmatophytes, each possessing different 
LCD distributions, implying that the applicability of the LDI may be limited to the marine environment.

Besides unknown producers, other issues with the LDI have been recognized. De Bar et al. (2016) and Lattaud et al. (2017a) observed that the LDI-derived temperatures in surface sediments near river mouths significantly deviated from satellite-derived SSTs. The diol distributions are characterized by elevated $C_{32}$ 1,15-diol abundance, due to the freshwater input where the $\mathrm{C}_{32}$ 1,15 diol occurs in high abundance (Rampen et al., 2014b). Consequently, applying the LDI in marine regions with riverine input should be done with caution. RodrigoGámiz et al. (2015) showed that for surface sediments and suspended particulate matter (SPM) in the subpolar region around Iceland, the LDI underestimated satellite-derived SST. Relatively high $\mathrm{C}_{28}$ and $\mathrm{C}_{30}$ 1,14-diol abundances were observed in this area, which are characteristic for Proboscia diatoms (Sinninghe Damsté et al., 2003; Rampen et al., 2007), although they were also identified in the estuarine species Apedinella radians (Rampen et al., 2011). Accordingly, the authors hypothesized that Proboscia diatoms (at least partially) contributed to the 1,13- and 1,15-diol production, and thereby compromised the LDI. For surface sediments in the Okhotsk Sea, also a subpolar region, the LDI correlated with SST, but this relationship was statistically different from the global calibration (Lattaud et al., 2018b). Lastly, down-core applications of the LDI have shown that the index is promising as a SST proxy but often reveals a slightly larger glacial-interglacial temperature amplitude than found for $U_{37}^{K \prime}$ and TEX 86 records (Rampen et al., 2012; Lopes dos Santos et al., 2013; Rodrigo-Gámiz et al., 2014; Jonas et al., 2017; de Bar et al., 2018).

Thus, despite promising down-core applications, questions remain about the calibration of this proxy and in which environments it can be applied. Therefore, in this study we 
141 substantially extended the initial global LDI core-top calibration of Rampen et al. (2012) with

142 literature data and newly generated data, adding 434 data points and considerably increasing

143 global coverage. Comparison with SST and salinity allowed us to determine the main controlling

144 factors and identify potential constraints on the applicability of the LDI.

145

146

147

148

149

150

151

152

153

154

155

156

157

158

159

160

161

162

163

\section{Materials and methods}

\subsection{Surface sediments}

We have combined the global core-top LCD data of Rampen et al. (2012) with other previously published LCD data and newly acquired core-top data. We re-evaluated the original LDI core-top dataset of Rampen et al. (2012), consisting of 209 measurements (black dots in Fig. 1), from which 161 LDI data points were used in the original calibration dataset. For this dataset we quantified additional diols, in particular the $\mathrm{C}_{28}$ 1,12-diol. Re-integration has led to minor changes in LDI values of $<0.08$. For eleven samples, we could not retrieve the original data and therefore we were not able to reintegrate the LCD peak areas (indicated in the Supplementary Table S1). Differences in contributions of the selected ions to the total ion counts $(\mathrm{m} / \mathrm{z}, 50-800)$ of saturated vs unsaturated LCDs were considered by applying correction factors as described by Rampen et al. (2009). For the dataset of Rampen et al. (2012), we applied two different correction factors to the two mass spectrometer (MS) systems on which the LCDs were analyzed (Supplementary Table S1). Additionally, were-integrated some previously published LCD data (pink dots in Fig. 1), i.e., the core-top sediment data from around Iceland of Rodrigo-Gámiz et al. (2015), the Iberian margin surface sediment data of de Bar et al. (2016), the Gulf of Lion, Amazon Basin, Berau delta and Kara Sea data of Lattaud et al. (2017a), the Mozambique Channel data of Lattaud et al. (2017b), the Okhotsk Sea data of Lattaud et al. (2018a) and part of 
164 the Black Sea data of Lattaud et al. (2018b). For the published LCD data of Lattaud et al.

165 (2017a,b), we have re-evaluated the quality of the raw data (i.e., chromatographic separation,

166 signal-to-noise levels) and based on this we used 97 of 160 data points. We adopted the LDI data

167 from the region around Australia (Smith et al., 2013), but did not have the original MS data and

168 thus were not able to re-evaluate the LCD distributions. Re-evaluation of data of de Bar et al.

169 (2016) showed that the fractional abundances of the unsaturated LCDs were not corrected for the

170 differences in contributions of the selected ions to the total mass spectrum, which is corrected

171 here (Supplementary Table S1). In total, the previously published data comprise 233 sediment

172 locations. Additionally, we analyzed 105 polar fractions for long-chain diols that had been

173 analyzed previously by Kim et al. (2008, 2010; white dots in Fig. 1) for the global TEX 86 core-

174 top calibration. Furthermore, we analyzed 186 new core-tops from several regions for a better

175 spatial coverage (white dots in Fig. 1). In total, 731 surface sediment samples were considered in 176 this study.

177

\subsection{Lipid extraction and instrumental analysis}

179 The 186 new surface sediments (mostly $0-1$ or $0-0.5 \mathrm{~cm}$ ) were freeze-dried and extracted

180 with an Accelerated Solvent Extractor (ASE 200; Dionex) using a dichloromethane:methanol

181 (DCM:MeOH) mixture (9:1; v/v) at a temperature of $100^{\circ} \mathrm{C}$ and a pressure of $7-8 \times 10^{6} \mathrm{~Pa}$.

182 Lipid extracts were dried under nitrogen and separated into three fractions (apolar, ketone, polar)

183 using activated $\left(2 \mathrm{~h}\right.$ at $\left.150^{\circ} \mathrm{C}\right) \mathrm{Al}_{2} \mathrm{O}_{3}$. Separation was achieved using the eluents hexane/DCM

184 (9:1; v/v), hexane/DCM (1:1; v/v) and DCM/MeOH $(1: 1 ; \mathrm{v} / \mathrm{v})$, respectively (Method 2 in

185 Supplementary Table S1). The polar fractions were silylated by the addition of pyridine and

186 N,O-bis(trimethylsilyl)trifluoroacetamide (BSTFA) and heating at $60^{\circ} \mathrm{C}$ for $20 \mathrm{~min}$. Prior to 
187 injection, ethyl acetate was added. GC-MS analyses were done on an Agilent 7890B gas

188 chromatograph interfaced with an Agilent 5977A mass spectrometer. Samples were injected on-

189 column at a starting temperature of $70^{\circ} \mathrm{C}$, which was programmed to $130^{\circ} \mathrm{C}$ at $20^{\circ} \mathrm{C} \mathrm{min}^{-1}$, and a

190 subsequent gradient of $4^{\circ} \mathrm{C} \mathrm{min}^{-1}$ to the end temperature of $320^{\circ} \mathrm{C}$, which was kept for $25 \mathrm{~min}$.

191 The GC was equipped with a fused silica column $(25 \mathrm{~m} \times 0.32 \mathrm{~mm})$ with a CP Sil-5 coating

192 (film thickness $0.12 \mu \mathrm{m}$ ). Helium was used as carrier gas with a constant flow of $2 \mathrm{ml} \mathrm{min}^{-1}$, and

193 the MS operated with an ionization energy of $70 \mathrm{eV}$. We identified the LCDs in full scan,

194 scanning from $\mathrm{m} / \mathrm{z} 50$ to $\mathrm{m} / \mathrm{z}$ 850, based on their characteristic fragmentation patterns (de Leeuw

195 et al., 1981; Versteegh et al., 1997). Quantification of the LCDs was achieved in selected ion

196 monitoring (SIM) mode of the characteristic fragmentation ions (i.e., $m / z$ 299, 313, 327 and 341;

197 Rampen et al., 2012). The LDI was calculated according to Rampen et al. (2012) integrating the

198 relevant peak areas in SIM mode (Eq. 1). For the calculation of fractional abundances, we

199 applied a correction factor for the relative contribution of the selected fragments during SIM to

200 the total ion counts for the saturated (16.1\%) vs unsaturated (9.1\%) LCDs.

Lipid extraction methods for re-analyzed polar fractions (from Kim et al., 2010) and the

202 LCD data which we re-evaluated or adopted, are described in the original literature. We have

203 classified these methods into five groups, indicated in the Supplementary Table S1 (Methods 1-

204 5). Generally, these methods differ in extraction protocol, i.e. ASE, ultrasonic extraction, Bligh

205 and Dyer, or ASE followed by saponification of the extract or in fractionation protocol, i.e. two

206 (apolar-polar) or three fraction (apolar-ketone-polar) separation using $\mathrm{Al}_{2} \mathrm{O}_{3}$, three fraction

207 separation using silica gel or separation of core lipids and intact polar lipids over silica gel. 


\subsection{Oceanographic data}

The LCD data were compared with temperature, salinity and nutrient data from the World Ocean Atlas 2013 (WOA13). Annual mean, seasonal sea surface temperatures $\left({ }^{\circ} \mathrm{C} ; 0 \mathrm{~m}\right.$ depth), temperatures for different depths, and salinity were obtained from the $0.25^{\circ}$ grid databases (decadal averages over the period of 1955 to 2012; Locarnini et al., 2013; Zweng et al., 2013). Annual mean phosphate and nitrate concentrations $\left(\mu \mathrm{mol}^{-1}\right)$ were obtained from the $1^{\circ}$ grid WOA13 databases (Garcia et al., 2014b). In case there was no temperature data for the $0.25^{\circ}$ grid corresponding to the core-top location, we adopted the SST value for the closest $0.25^{\circ}$ grid. For SST, we used data within $1^{\circ}$ distance; if not available, we did not include the data. Exceptions are thirteen Antarctic sediments for which we used seasonal SST data of $1-2^{\circ}$ degrees away, as in these regions SST data were generally scarcer. For salinity, we used values within $1.5^{\circ}$ distance of the core-top location, and for phosphate and nitrate we stayed within a $3^{\circ}$ radius. For a principal component analysis, we also obtained oxygen saturation $(\%)$, dissolved oxygen (ml $1^{-}$

${ }^{1}$ ) and silicate concentrations $\left(\mu \mathrm{mol} 1^{-1}\right)$ from the World Ocean Atlas 2013 (Garcia et al., 2014a,b). The oxygen and silicate data were obtained from $1^{\circ}$ grid databases, and only data of the grids corresponding to the core-top locations were used; i.e., in case not available, we have not adopted data from grids nearby.

\subsection{Statistical analysis}

We performed Principal Component Analysis (PCA) on the fractional abundances of the various LCDs, annual mean SST, salinity, and phosphate and nitrate concentrations, using the XLSTAT software (Addinsoft, 2018) (Fig. 3). Furthermore, PCA analysis was done on LDI, dissolved oxygen, oxygen saturation, nitrate, phosphate, silicate, salinity, SST and LDI 
232 (Supplementary Fig. S4). When an LCD was not detected, its fractional abundance was

233 considered zero. In both PCA, data points were not plotted in case data for one or more of the

234 parameters (i.e., LDI, salinity, SST, phosphate, etc.) was missing, or if the fractional abundance

235 of one of the long-chain diols was unknown (e.g., due to co-elution). R statistical software was

236 used for multiple linear regression analyses and for the comparison of different regression slopes

237 by means of analysis of covariance (ANCOVA).

\section{Results and discussion}

We have combined several data sets to extend the core-top calibration of the LDI, as originally published by Rampen et al. (2012), to re-assess the calibration of the index, and to

242 identify potential constraints on the proxy. We have re-evaluated the core-top data of Rampen et 243 al. (2012), and re-evaluated and adopted previously published LCD data (Smith et al., 2013;

244 Rodrigo-Gámiz et al., 2015; de Bar et al., 2016; Lattaud et al., 2017a,b, 2018a,b) and added new 245 core-top data, which in total resulted in LCD distributions from 731 core-tops. Of these 731

246 sediment samples, we have excluded 136 samples because of quantification limit issues, related 247 to high backgrounds obscuring the signals of the LDI-diols or low abundances of all LCDs, 248 compromising the reliability of the LDI values. Furthermore, for certain samples fractional 249 abundances are given but not the LDI (Supplementary Table S1), as the relative diol abundances 250 were considered too low for index calculation. For instance, some core-tops are dominated by 251 1,14-diols, for which the Diol Indices were calculated, but not the LDI as the 1,13- and 1,15252 diols were present in too low amounts. In total we obtained 595 LDI data points and cover an 253 annual mean temperature range of $-1.8^{\circ} \mathrm{C}$ to $30.3^{\circ} \mathrm{C}$ (Fig. 2; Supplementary Table S1). Although 
254 we have improved global coverage compared to Rampen et al. (2012), it must be noted that almost $40 \%$ of our surface sediments originate from the tropical temperature regime, i.e. $>25^{\circ} \mathrm{C}$.

We have linearly cross-correlated our LDI core-top data with annual mean SST (WOA13; Locarnini et al., 2013), resulting in a positive regression and a coefficient of determination $\left(\mathrm{R}^{2}\right)$ of 0.82 (Fig. 2), confirming that the LDI contains a strong temperature signal. The relationship $(\mathrm{LDI}=0.0323 \times \mathrm{SST}+0.1111)$ is statistically not different from the slope and intercept (ANCOVA $p$-value > 0.1) of the original LDI-relation as proposed by Rampen et al. (2012; Eq. 2). Additionally, we performed a Principal Component Analysis to reveal possible relationships between environmental factors and long-chain diol proxies (Fig. 3a) and between individual LCDs (Fig. 3b). The first component (PC) in the first PCA (Fig. 3a) explains 51.1\% of the variance, with the strongest positive loadings of annual mean SST and LDI, suggesting that temperature is the main control of variance on the first component, which is confirmed by the strong correlation between the Factor 1 scores and SST, with a coefficient of determination $\left(\mathrm{R}^{2}\right)$ of 0.79 (Fig. 3c). The $\mathrm{C}_{28}$ and $\mathrm{C}_{30}$ 1,13-diols load opposite of the $\mathrm{C}_{30}$ 1,15-diol on Factor 1 (Fig. 3b). This is consistent with the $\mathrm{C}_{30}$ 1,15-diol abundance, and thus the LDI, being higher with higher SST while the 1,13-diol is more abundant with lower SST (cf. Rampen et al., 2012). Accordingly, the variance explained by Factor 1 (28\%) in Fig. 3b is also likely primarily temperature, confirmed by the relatively high coefficient of determination $\left(\mathrm{R}^{2}=0.66\right)$ for the scores of Factor 1 and annual mean SST (Fig. 3e). The $\mathrm{C}_{32}$ 1,15-diol has almost no factor loading on the Factor 1 axis in both plots, suggesting that temperature has minimal influence on the abundance of the $\mathrm{C}_{32}$ 1,15-diol, which is consistent with the results of Rampen et al. (2012). The fractional abundance of the $\mathrm{C}_{32}$ 1,15-diol (cf. de Bar et al., 2061) has a strong negative loading on the axis of Factor 2 (Fig. 3a), where salinity shows the strongest positive 
loading. The abundance of the $\mathrm{C}_{32}$ 1,15-diol has previously been linked to freshwater influence (e.g., Rampen et al., 2014; de Bar et al., 2016; Lattaud et al., 2017a; 2017b). Salinity is used as an indicator of freshwater input, suggesting the variance explained by Factor 2 is significantly influenced by freshwater input (and/or salinity), confirmed by the coefficient of determination $\left(\mathrm{R}^{2}\right)$ of 0.56 (Fig. 3d).

A number of data points do not fall close to the calibration line and the decrease in coefficient of determination $\left(\mathrm{R}^{2}\right)$ from 0.97 of the original calibration of Rampen et al. (2012) to 0.82 in this study. In the following sections we will discuss factors potentially responsible for this increased scatter in the LDI calibration and evaluate possible constraints on the proxy.

\subsection{Non-marine LCD contributions}

Previous studies have shown that river outflow, i.e. freshwater input, can compromise the LDI (de Bar et al., 2016; Lattaud et al., 2017a), although the effect of riverine input on the LDI is likely specific for each region. For instance, de Bar et al. (2016) observed lower LDI-derived SSTs than satellite-derived SSTs in surface sediments close to the river mouths on the Portuguese margin, whereas Lattaud et al. (2017b) obtained LDI SSTs which were significantly higher than satellite SSTs for Kara Sea sediments closest to the Yenisei River. Surface sediments deposited in low salinity environments ( $<32 \mathrm{ppt})$, which are impacted by river inflow, are mainly derived from the Hudson Bay (salinity 26-31 ppt), the Baltic Sea (7-30 ppt), the Black Sea (11$18 \mathrm{ppt})$, and the Kara Sea (10-32 ppt).While, despite the riverine input, the annual mean salinity at the Portuguese margin in the region studied by de Bar et al. (2016) is above 32 ppt. The LDI values from the Baltic Sea, the Gulf of St. Lawrence and the Black Sea are clearly positioned above the regression line (Fig. 2a) with temperature differences up to ca. $+14.5^{\circ} \mathrm{C}$. This might 
suggest that the LDI is unlikely to work in low salinity environments, consistent with Rampen et al. (2014b) who observed that the LDI cannot be applied to lakes. Although there is no significant relationship between salinity and the LDI or its residual error, plotting the residual errors of the LDI calibration vs salinity shows that LDI estimates for areas with the lowest salinities (Supplementary Fig. S1b) overestimate SST. Accordingly, when we exclude surface sediments deposited at salinities < 32 ppt (57 samples originating from the Baltic Sea, the Black Sea, the Hudson Bay, the Gulf of St. Lawrence and the Kara Sea), the coefficient of determination improves $\left(\mathrm{R}^{2}=0.86\right.$; Fig. $\left.2 \mathrm{c}\right)$. However, note that this also results in a change in calibration slope from 0.0323 to 0.0339 (Fig. 2). The core-tops from the Hudson Bay and the Gulf of St. Lawrence originate from the dataset of Rampen et al. (2012) but were also excluded in the original core-top calibration. It remains remarkable but unclear why the samples from the Portuguese margin, also influenced by freshwater but with salinities $>32 \mathrm{ppt}$, do not follow this trend in overestimating SST, but provides lower SST estimates instead.

An alternative way to screen sediments for the impact of freshwater influence could be to use the abundance of the $\mathrm{C}_{32}$ 1,15-diol, which is often elevated near rivers (Versteegh et al., 1997; 2000; Rampen et al., 2014b; de Bar et al., 2016; Lattaud et al., 2017a; 2017b). However, there is no clear relation between high $\mathrm{C}_{32}$ 1,15-diol abundances and residual errors of the LDI (Supplementary Fig. S1a) and removal of core-tops with high $\mathrm{C}_{32}$ 1,15-diol abundances $>0.3$, only results in a very small improvement in the coefficient of determination $\left(\mathrm{R}^{2}=0.83\right.$; Supplementary Fig. S1). Accordingly, the fractional abundance of the $\mathrm{C}_{32}$ 1,15-diol does not provide a strong indication for biases in the LDI caused by freshwater input on a global scale. We also tested if $\mathrm{C}_{32}$ 1,15-diol abundances can be used to correct for a possible salinity effect, by applying multiple linear regression with SST and calculated relative abundances of $\mathrm{C}_{28}$ and $\mathrm{C}_{30}$ 
1,13- and $\mathrm{C}_{30}$ and $\mathrm{C}_{32}$ 1,15-diols from the original dataset. The outcome did not result in a higher coefficient of determination with SST $\left(\mathrm{R}^{2}=0.83\right)$, suggesting $\mathrm{C}_{32}$ 1,15-diol abundances cannot be used to correct for salinity effects. In any case, this study, as well as other studies (e.g., Rampen et al., 2012; de Bar et al., 2016; Lattaud et al., 2017a), show that the application of the LDI in low salinity environments or very close near river mouths may be problematic. The weak, non-significant correlations between the LDI and its residual errors vs salinity or the fractional abundance of the $\mathrm{C}_{32}$ 1,15-diol indicates that neither salinity nor $\mathrm{C}_{32}$ 1,15-diol are conclusive indications for the compromising influence of freshwater. This influence is most likely specific for every region, and may depend, amongst others, on the freshwater sources from which longchain diols can derive. Rivers, lakes, estuaries, inland seas, wetlands, sea/land ice, etc. may each contain different diol producers, and therefore contribute different long-chain diol distributions.

\subsection{Influence of Proboscia lipids on the LDI}

Our dataset includes the core-top data of Rodrigo-Gámiz et al. (2015) of the subpolar region around Iceland. However, as mentioned in the introduction, the LDI substantially underestimates satellite SSTs in this region, likely because Proboscia diatoms seem to be at least a partial source of the 1,13-diols. Since this may also occur in other regions, we screened for the influence of Proboscia diatoms using two Diol Indices based on 1,14-diols vs the 1,15-diol and vs the 1,13 diols (Rampen et al., 2008; Willmott et al., 2010, respectively). Cross-correlating the temperature difference between annual mean SST and the LDI-regression based SST (from Fig. 2c) with these indices (Supplementary Fig. S2), does not reveal strong correlations, although several sediments have a high Diol Index 1 (Rampen et al., 2008) as well as a cold bias in the LDI-derived SST. However, most core-tops with such a high Diol Index do not reveal this cold 
bias. Thus, the Diol Indices do not provide an unambiguous indication for a potential bias on the LDI caused by Proboscia LCD contribution.

We closely examined the data points which fall well below the LDI regression line, i.e., many of the Iceland data-points (pink diamonds), the Okhotsk Sea (brown triangles) and the North Atlantic Ocean (yellow squares; transect Ireland-Greenland) (Fig. 2a). Examination of the chromatograms of these respective samples often showed an atypical LCD distribution compared to other marine sediments (Fig. 4). One sediment from the Gulf of Mexico also shows this unusual distribution, and interestingly this is the only data-point of this region which also substantially underestimates SST when compared to the LDI regression (LDI 0.43, SST $24.5^{\circ} \mathrm{C}$; Fig. 2a). These sediments are characterized by high mono-unsaturated and saturated 1,14-diol abundances, but also relatively high $\mathrm{C}_{26}$ and $\mathrm{C}_{28}$ 1,12-diols. The Okhotsk Sea sediments also contain relatively high abundances of the $\mathrm{C}_{26}$ 1,13-diol. The $\mathrm{C}_{28}$ 1,12-diol has been observed in low amounts in lake sediments (Shimokawara et al., 2010; Rampen et al., 2014a), freshwater eustigmatophyte algae (Volkman et al., 1999; Rampen et al., 2014a) and in Proboscia diatoms (Rampen et al., 2007) as well as in marine sediments with high 1,14-diol concentrations (Willmott et al., 2010; Rampen et al., 2007; ten Haven and Rullkötter, 1991; de Bar et al., 2018). The $\mathrm{C}_{26}$ 1,12-diol has been observed in cultures of $P$. inermis and $P$. indica (Rampen et al., 2007), and in Eocene-Oligocene (between ca. 50-30 Ma) sediments from the Falkland Plateau (southwest Atlantic Ocean; Plancq et al., 2014) and the New Jersey shelf (de Bar et al., 2019). In sediments where we detected relatively high abundances of the $\mathrm{C}_{26}$ and $\mathrm{C}_{28}$ 1,12-diols, we also detected relatively high abundances of the $\mathrm{C}_{27}$ and $\mathrm{C}_{29}$ 12-hydroxy and $\mathrm{C}_{28}$ and $\mathrm{C}_{30}$ 13-hydroxy methyl alkanoates (Fig. 4). Sinninghe Damsté et al. (2003) and Rampen et al. (2007) observed $\mathrm{C}_{27}$ and $\mathrm{C}_{29} 12$ - hydroxy methyl alkanoates in cultures of $P$. indica, $P$. alata and P. inermis. 
Small amounts of the $\mathrm{C}_{28}$ and $\mathrm{C}_{30}$ 13-hydroxy methyl alkanoates were detected solely in $P$. indica. Since, to date, Proboscia is the only group of organisms known to produce these hydroxyl methyl alkanoates and 1,14- and 1,12-diols, this is a very strong indication that the LCDs and mid-chain hydroxy methyl alkanoates in these sediments are produced by Proboscia species. However, the unusual distributions with the high $\mathrm{C}_{26}$ and $\mathrm{C}_{28}$ 1,12-diols and $\mathrm{C}_{28}$ and $\mathrm{C}_{30}$ 12-hydroxy methyl alkanoates detected in several sediments compared to those of cultures also strongly suggest that they are sourced by Proboscia species that have not yet been cultured and evaluated for LCDs.

The fact that the sediments with unusual distributions of 1,12-diols all reveal very low LDI values compared to the LDI regression, indicates that particular Proboscia species likely contribute 1,13-diols, thereby compromising the LDI. Consequently, we calculated the fractional abundance of the $\mathrm{C}_{28}$ 1,12-diol (with respect to the $\mathrm{C}_{28}$ 1,12-, 1,13-, 1,14-, $\mathrm{C}_{30}$ 1,13-, 1,14- and 1,15-diols):

$F \mathrm{C}_{28}$ 1,12-diol $=\left[\mathrm{C}_{28} 1,12-\mathrm{diol}\right] /\left[\mathrm{C}_{28} 1,12+\mathrm{C}_{28} 1,13+\mathrm{C}_{28} 1,14+\mathrm{C}_{30} 1,13+\mathrm{C}_{30} 1,14+\mathrm{C}_{30} 1,15\right.$-diols $]$

and subsequently plotted the $F_{28}$ 1,12-diol against the residual temperature errors of the LDI calibration (i.e., LDI SST - AM SST; Fig. 5). This showed that the fractional abundance of the $\mathrm{C}_{28}$ 1,12-diol is below 0.1 for the large majority of the sediments ( $95 \%$ of total), but when the fractional abundance increases, the LDI is biased towards colder temperatures (up to ca. $-14{ }^{\circ} \mathrm{C}$ difference). For this reason, the relative abundance of the $\mathrm{C}_{28}$ 1,12-diol might serve as a better indication for the influence of certain Proboscia species on the LDI than the abundance of 1,14diols. Interestingly, the regions in which we observe Proboscia influence on the LDI as signified by the high $\mathrm{C}_{28}$ 1,12-diol abundance are, except for the one core-top in the Gulf of Mexico, 
392 located between 45 and $65^{\circ} \mathrm{N}$, suggesting that these Proboscia diatoms thrive mainly in these

393 high-latitude areas. An alternative manner to correct for the influence of Proboscia diatoms is 394 using multiple linear regression of SST and $F_{28}$ 1,12-diol. However, this did not result in an 395 improved correlation, possibly because the relative amount of 1,13-diols produced by Proboscia 396 is not a constant variable but is dependent on several environmental factors such as temperature 397 and nutrient availability.

\subsection{Residual errors in estimation}

Although our new correlation between LDI and annual mean SST is strong, there is also considerable scatter. Indeed, the resulting calibration error, i.e. the standard deviation on the residual errors, is $3.0^{\circ} \mathrm{C}$, which is higher than the $2.0^{\circ} \mathrm{C}$ of the original calibration of Rampen et al. (2012). The residual errors of the LDI-derived SSTs (LDI SST - annual mean SST) are between -11.1 and $13.3^{\circ} \mathrm{C}$ ), without a relationship between the residuals and annual mean SST (Fig. 6b). This range of residual errors is relative large, potentially limiting the application of the LDI as an SST proxy. Also, as can be seen in Fig. 6b, the residuals are not randomly distributed, signifying that the linear regression model does not explain all trends in the dataset. Different 
415 statistical models could be more appropriate to define the relationship between the LDI and SST,

416 however in addition to temperature, other environmental and/or biosynthetic factors may also

417 control the distribution of the 1,13- and 1,15-diols. LCD sources may have a seasonal

418 occurrence, thereby registering seasonal instead of annual mean SST, and the LDI-SST

419 relationship may be affected by regional environmental conditions such as freshwater input,

420 nutrient conditions, and oxygen concentrations. To assess which water column parameters affect

421 the LDI, we performed a PCA on the LDI, SST, salinity, phosphate, nitrate and silicate

422 concentrations, dissolved oxygen, and percent oxygen saturation values from samples from the

423 final calibration dataset (Supplementary Fig. S4). SST and the LDI show the largest factor

424 loadings for the first Principal Component which explains 51.8\% of the total variance, indicating

425 that temperature is the most important factor for explaining the variation in the data. Salinity

426 loads in the same direction as SST and LDI, which may potentially be caused by the global

427 correlation between salinity and SST. The SST and LDI factor loadings for the second Principal

428 Component (24.4\%) are relatively low and in the same range. Hence, the PCA results provide

429 support for the idea that SST is the most important parameter affecting the LDI.

430 Nevertheless, this does not exclude the possibilities that in certain regions correlations

431 between LDI and SST are absent or different. For example, it was shown for the Iberian margin

432 that these LDI data were likely compromised by river outflow, despite a salinity > 32 ppt (de Bar

433 et al., 2016), causing a large range of LDI values despite the small range in SST. The cross-

434 correlation of the LDI with mean seasonal SSTs reveals that the LDI correlates best with summer

435 temperatures $\left(\mathrm{R}^{2}=0.90\right.$; Supplementary Fig. S3), also providing a more random distribution of

436 the residuals and a more consistent calibration error over the whole temperature range. The LDI

437 might be more reflective of seasonal temperatures rather than annual mean temperatures, 
438 depending on regional growth seasons of the source organisms which in turn depend on nutrient 439 and upwelling conditions (e.g., Lattaud et al., 2019). In that case, an increase in scatter of the 440 calibration is not in the LDI, but in the temperature the LDI is calibrated against. Another issue might be that the proxy signal is not reflecting surface conditions. However, when correlating the LDI with annual mean sea temperatures from different water depths, highest coefficients of determination were observed for temperatures from the upper $30 \mathrm{~m}$ of the water column $\left(\mathrm{R}^{2}=\right.$ around 0.88), similar to Rampen et al. (2012). This is also in agreement with Balzano et al. (2018) who assessed long-chain diol concentrations for different water depths along a longitudinal transect across the tropical Atlantic, where highest concentrations were observed for the upper 20-30 m. Moreover, de Bar et al. (2019) calculated LDI temperatures for sediment trap time series in the tropical Atlantic, the Mozambique Channel and the Cariaco Basin, and for all three regions the flux-weighted annual mean temperatures agreed well with mean annual surface temperatures. Thus, whereas seasonality may explain some of the scatter, there are no indications that different depth habitats play a significant role.

To further illustrate that the existence of non-random residuals can partially be explained by regional differences, the residual errors are plotted in Fig. 7 on a global map. The regions where the LDI temperatures differ more than \pm 2 SD from the regression line are mainly derived from the Mediterranean, the Equatorial Pacific and the Iberian margin. The LDI of the surface sediments in the Mediterranean overestimate annual mean SST (up $6.6^{\circ} \mathrm{C}$ ) while the core-tops of the equatorial Pacific show severe underestimation (up to $-11.1^{\circ} \mathrm{C}$ ). In the Pacific sediments, the 1,14-diols are also relatively high in abundance (30-90\%), but the samples do not reveal unusual LCD distributions, i.e. a high abundance of 1,12-diols. Moreover, the PCA biplot does not show that the Equatorial Pacific or the Mediterranean data cluster as distinct groups separated from the 
other data (Fig. 3). The reasons for the cold and warm bias in these regions remain unknown, but may be due to differences in regional conditions. For instance, in the Equatorial Pacific, the LDI temperature signal might be related to the seasonal upwelling of cold waters. If the producers of 1,13 and 1,15 LCDs mainly thrive under high-nutrient conditions induced by upwelling, or during stagnant conditions, then the LDI will reflect temperatures during these times. In general, if the source organisms are seasonally blooming, then the LDI will likely reflect a seasonal rather than annual mean SST.

Another uncertainty is the age of the core-top material extracted. Although many sediments represent the upper 0.5 to $1 \mathrm{~cm}$ (with a few comprising the upper $2 \mathrm{~cm}$ ), they can represent different ages, as sedimentation rates can differ significantly per location, resulting in different time lengths reflected by the sediment. A more careful assessment of the age represented by each surface sediment can potentially improve the calibration of the LDI. The LDI data at the upper end of the calibration $\left(>16^{\circ} \mathrm{C}\right)$ showed a reduction in slope. However, application of a third order polynomial equation results only in a moderate increase in coefficient of determination to 0.90 (data not shown). Therefore, we propose to use equation 4 as the new calibration of LDI to SST, although we realize that the linear regression model does not sufficiently explain all data and other models may be needed. More regional and time-series studies are needed to assess regional influences on the LDI, and future research should also focus on the identification of the LDI producers. This could lead to a better understanding of the mechanisms behind the relationship between the LDI and temperature as well as the effect of differences in the source organisms. 


\subsection{Implications for LDI temperature reconstructions}

Our new extended LDI calibration is statistically similar to the original calibration proposed by Rampen et al. (2012), suggesting that previous temperature reconstructions based on the LDI (e.g., Lopes dos Santos et al., 2013; Warnock et al., 2017; Jonas et al., 2017) likely do not require major adjustments. The maximum temperature difference between the previous SST calibration and the present calibration is $+0.45^{\circ} \mathrm{C}$ at the lower end of the calibration (LDI=0) and $-0.02^{\circ} \mathrm{C}$ at the upper end $(\mathrm{LDI}=1)$. However, due to the substantial increase in data-points included in the calibration, the residual error increased from $2{ }^{\circ} \mathrm{C}$ to $3{ }^{\circ} \mathrm{C}$, which is larger than that of the $U_{37}^{K \prime}\left(1.5^{\circ} \mathrm{C}\right)$ and the $T E X_{86}^{H}\left(2.5^{\circ} \mathrm{C}\right)$. Possibly, differences between proxy values observed in sediment records may now fall within proxy errors.

Importantly, our results provide new constraints on the application of the LDI. Firstly, the LDI should not be applied in low-salinity environments and environments substantially influenced by river runoff. These types of conditions can, to some degree, be assessed for past environments by organic proxies (e.g. the BIT index, the $\delta \mathrm{D}$ of alkenones, dinocyst assemblages) or inorganic proxies (e.g. mineral composition). Secondly, high abundances of the $\mathrm{C}_{26}$ and $\mathrm{C}_{28}$ 1,12-diols and $\mathrm{C}_{27}$ and $\mathrm{C}_{29}$ 12-hydroxy and $\mathrm{C}_{28}$ and $\mathrm{C}_{30}$ 13-hydroxy methyl alkanoates hint at LCD contributions from Proboscia spp., and we advise against using LDI data when the fractional abundance of the $\mathrm{C}_{28}$ 1,12-diol (vs $\mathrm{C}_{28}$ 1,12-, 1,13-, 1,14-, $\mathrm{C}_{30}$ 1,13-, 1,14- and 1,15diols) is $>0.1$. This LCD has probably been ignored in most of the previous studies on longchain diols, but our data show it is useful to include it in future studies to assess the potential influence of Proboscia LCD contribution on the LDI. Quantification of the $\mathrm{C}_{28}$ 1,12-diol does not require any modification of the SIM analysis method used for the standard 1,13-, 1,14- and 1,15-diols as it will be detected by the $m / z 327$ ion. Furthermore, caution is advised when 
applying the LDI in case of high and/or variable 1,14-diol abundances (e.g., Equatorial Pacific).

Since previous LDI records have not reported the abundance of $\mathrm{C}_{28}$ 1,12-diols we cannot evaluate whether these were compromised by Proboscia-derived LCDs. However, de Bar et al. (2019) calculated the LDI for the ages of $\sim 11,18,33,41$ and 50 Ma for the Bass River core (New Jersey, USA) and observed that the LDI-derived temperatures did not agree with other paleotemperature records for this core, with LDI temperatures being between 2 to $14{ }^{\circ} \mathrm{C}$ lower as compared to the $T E X_{86}^{H}$-derived SSTs. Interestingly, the $F C_{28}$ 1,12-diol varied between 0.2 and 1 for the ages of 18, 33, 41 and 50 Ma, potentially suggesting a Proboscia influence on the LDI at this location.

\section{Conclusions}

We have extended the global core-top temperature calibration of the Long chain Diol Index and confirmed that LDI values are strongly correlated with annual mean SST, but with a considerable increase in scatter and a decrease in the coefficient of determination $\left(\mathrm{R}^{2}\right.$ reduced from 0.97 to 0.82 ). We observed that most surface sediments with low salinities, in particular sediments from the Baltic Sea and Black Sea, overestimate LDI-derived temperatures, and exclusion of these sediments ( salinity $<32 \mathrm{ppt})$ improved the coefficient of determination $\left(\mathrm{R}^{2}=\right.$ 0.86). The fractional abundance of the $\mathrm{C}_{32}$ 1,15-diol is not a consistent indicator for freshwater influence on the LDI, since its ability to trace riverine input is likely region-specific. Examination of diol distributions with high input of 1,14-diols from Proboscia diatoms shows that the Diol Indices are not good indicators for identifying biases in the LDI, but that high abundances of the $\mathrm{C}_{26}$ and $\mathrm{C}_{28}$ 1,12-diols, as well as the $\mathrm{C}_{27}$ and $\mathrm{C}_{29}$ 12-hydroxy and $\mathrm{C}_{28}$ and $\mathrm{C}_{30}$ 13-hydroxy methyl alkanoates, are associated with a cold bias in the LDI-based temperatures. 
Therefore, we have defined a cut-off of 0.1 in the $\mathrm{C}_{28}$ 1,12-diol fractional abundance, which further improved the correlation between the LDI and annual mean SST. The new calibration between the $\mathrm{LDI}$ and SST $\left(\mathrm{LDI}=0.0325 \times \mathrm{SST}+0.1082 ; n=514 ; \mathrm{R}^{2}=0.88\right)$ covers a temperature range between -3.3 and $27.4^{\circ} \mathrm{C}$ with a calibration error of $3{ }^{\circ} \mathrm{C}$. However, the linear regression model does not sufficiently explain all of our data, due to the presence of non-random residuals in our dataset. More research is needed to constrain local and seasonal influences on the LDI, as well as to identify the source organism, in order to reduce the calibration uncertainty. The relationship is statistically similar to the Rampen et al. (2012) calibration, and thus supports previous down-core LDI applications. Our results confirm that the LDI can be used as a proxy for the reconstruction of annual mean SST in marine sediment cores, but with caveats, i.e. it should not be applied in low-salinity/freshwater influenced regions, or when the fractional abundance of the $\mathrm{C}_{28}$ 1,12-diol (vs $\mathrm{C}_{28} 1,12-, 1,13-, 1,14-, \mathrm{C}_{30} 1,13-, 1,14$ - and 1,15-diols) is > 0.1. Accordingly, re-evaluation of the reliability of the LDI records in terms of freshwater influence (salinity, $\mathrm{C}_{32}$ 1,15-diol abundance) and Proboscia contribution (high/variable 1,14-diol abundances, $\mathrm{C}_{28}$ 1,12-diol abundance) is recommended. Finally, in some regions there seems to be no, or a weak relation between the LDI and annual mean SST, for reasons which are presently unclear, thereby limiting the application of the LDI.

\section{Acknowledgements}

We thank Dr. Andy Revil and John Volkman, two anonymous reviewers and Liz Sikes for useful comments which improved the manuscript. We are grateful to various people who have worked-up or provided core-top sediments: TjerkVeenstra, and Steven D'Hondt for Pacific core-tops recovered during the R/V Knorr expedition 195-3 (US National Science Foundation 
grant OCE-0752336), Isla Castañeda (Mozambique Channel), Ivan Tomberg and Roselyne Buscail (Gulf of Lion), Claudia Zell and David Hollander (Amazon Basin), Kees Booij (Berau Delta), Cindy de Jonge, Alina Stadnitskaia and Georgy Cherkashov (Kara Sea), Li Lo (Okhotsk Sea), Marcel van der Meer (Mediterranean), Laura Villanueva (Black Sea) and Zeynep Erdem (Chilean margin). We thank Allert Bijleveld for statistical advice. This research has been funded by the European Research Council (ERC) under the European 555 Union's Seventh Framework Program (FP7/2007-2013) ERC grant agreement [339206] to S.S. S.S. and J.S.S.D. receive funding from the Netherlands Earth System Science Center (NESSC) through a Gravitation grant from the Dutch ministry for Education, Culture and Science (grant number 024.002.001).

\section{Appendices}

Supplementary data associated with this article can be found in the online version, at ..., as well as in the PANGAEA database (DOI: ...).

\section{References}

Anagnostou, E., John, E.H., Edgar, K.M., Foster, G.L., Ridgwell, A., Inglis, G.N., Pancost, R.D., Lunt, D.J., Pearson, P.N., 2016. Changing atmospheric $\mathrm{CO}_{2}$ concentration was the primary driver of early Cenozoic climate. Nature 533, 380.

Balzano, S., Lattaud, J., Villanueva, L., Rampen, S.W., Brussaard, C.P.D., van Bleijswijk, J., Bale, N.J., Sinninghe Damsté, J.S., Schouten, S., 2018. A quest for the biological sources of long chain alkyl diols in the western tropical North Atlantic Ocean. Biogeosciences 15, $5951-5968$. 
Bijl, P.K., Schouten, S., Sluijs, A., Reichart, G.-J., Zachos, J.C., Brinkhuis, H., 2009. Early Palaeogene temperature evolution of the southwest Pacific Ocean. Nature 461, 776-779. Brassell, S.C., Eglinton, G., Marlowe, I.T., Pflaumann, U., Sarnthein, M., 1986. Molecular stratigraphy: A new tool for climatic assessment. Nature 320, 129-133.

Conte, M.H., Sicre, M.A., Rühlemann, C., Weber, J.C., Schulte, S., Schulz-Bull, D., Blanz, D., 2006. Global temperature calibration of the alkenone unsaturation index $\left(U_{37}^{K \prime}\right.$ in surface waters and comparison with surface sediments. Geochemistry, Geophysics, Geosystems 7, 1-22.

Conte, M.H., Thompson, A., Eglinton, G., 1995. Lipid biomarker diversity in the coccolithophorid Emiliania huxleyi (Prymnesiophyceae) and the related species Gephyrocapsa oceanica. Journal of Phycology 31, 272-282.

Conte, M.H., Weber, J.C., King, L.L., Wakeham, S.G., 2001. The alkenone temperature signal in western North Atlantic surface waters. Geochimica et Cosmochimica Acta 65, 42754287.

de Bar, M.W., Dorhout, D.J.C., Hopmans, E.C., Rampen, S.W., Sinninghe Damsté, J.S., Schouten, S., 2016. Constraints on the application of long chain diol proxies in the Iberian Atlantic margin. Organic Geochemistry 101, 184-195.

de Bar, M.W., Rampen, S.W., Hopmans, E.C., Sinninghe Damsté, J.S., Schouten, S., 2019. Constraining the applicability of organic paleotemperature proxies for the last 90 Myrs. Organic Geochemistry 128, 122-136.

de Bar, M.W., Stolwijk, D.J., McManus, J.F., Sinninghe Damsté, J.S., Schouten, S., 2018. A Late Quaternary climate record based on long-chain diol proxies from the Chilean margin. Climate of the Past 14, 1783-1803. 
de Leeuw, J.W., Rijpstra, W.I.C., Schenck, P.A., 1981. The occurrence and identification of $\mathrm{C}_{30}$, $\mathrm{C}_{31}$ and $\mathrm{C}_{32}$ alkan-1,15-diols and alkan-15-one 1-ols in Unit I and Unit II Black Sea sediments. Geochimica et Cosmochimica Acta 45 2281-2285.

Emiliani, C., 1955. Pleistocene temperatures. The Journal of Geology 63, 538-578.

Foster, G.L., Royer, D.L., Lunt, D.J., 2017. Future climate forcing potentially without precedent in the last 420 million years. Nature Communications 8. DOI: 10.1038/ncomms14845 (2017).

Gal, J.-K., Kim, J.-H., Shin, K.-H., 2018. Distribution of long chain alkyl diols along a southnorth transect of the northwestern Pacific region: Insights into a paleo sea surface nutrient proxy. Organic Geochemistry 119, 80-90.

Garcia, H.E., R.A. Locarnini, T.P. Boyer, J.I. Antonov, O.K. Baranova, M.M. Zweng, J.R. Reagan, D.R. Johnson, 2014a. World Ocean Atlas 2013, Volume 3: Dissolved Oxygen, Apparent Oxygen Utilization, and Oxygen Saturation. In: Levitus, S and Mishonov, A. (Eds.), NOAA Atlas NESDIS 75, 27 pp.

Garcia, H.E., Locarnini, R.A., Boyer, T.P., Antonov, J.I., Baranova, O.K., Zweng, M.M., Reagan, D.R., Johnson, 2014b. World Ocean Atlas 2013. Vol. 4: Dissolved Inorganic Nutrients (phosphate, nitrate, silicate). In: Levitus, S and Mishonov, A. (Eds.), NOAA Atlas NESDIS 76, 25 pp.

Gelin, F., Boogers, I., Noordeloos, A.A.M., Sinninghe Damsté, J.S., Riegman, R., de Leeuw, J.W., 1997. Resistant biomacromolecules in marine microalgae of the classes Eustigmatophyceae and Chlorophyceae: Geochemical implications. Organic Geochemistry 26, 659-675. 
IPCC, 2014. Climate Change 2014: Synthesis Report. Contribution of Working Groups I, II and III to the In: Core Writing Team, Pachauri, R.K., Meyer, L.A. (Eds.), Fifth Assessment Report of the Intergovernmental Panel on Climate Change. IPCC, Geneva, Switzerland, $151 \mathrm{pp}$.

Jonas, A.S., Schwark, L., Bauersachs, T., 2017. Late Quaternary water temperature variations of the Northwest Pacific based on the lipid paleothermometers $T E X_{86}^{H}, U_{37}^{K \prime}$ and LDI. Deep Sea Research Part 1 Oceanographic Research Papers 125, 81-93.

Kim, J.-H., Schouten, S., Hopmans, E.C., Donner, B., Sinninghe Damsté, J.S., 2008. Global sediment core-top calibration of the TEX 86 paleothermometer in the ocean. Geochimica et Cosmochimica Acta 72, 1154-1173.

Kim, J.-H., van der Meer, J., Schouten, S., Helmke, P., Willmott, V., Sangiorgi, F., Koç, N., Hopmans, E.C., Sinninghe Damsté, J.S., 2010. New indices and calibrations derived from the distribution of crenarchaeal isoprenoid tetraether lipids: Implications for past sea surface temperature reconstructions. Geochimica et Cosmochimica Acta 74, 4639-4654.

Lattaud, J., Dorhout, D., Schulz, H., Castañeda, I.S., Schefuß, E., Sinninghe Damsté, J.S., Schouten, S., 2017b. The $\mathrm{C}_{32}$ alkane-1,15-diol as a proxy of late Quaternary riverine input in coastal margins. Climate of the Past 13, 1049-1061.

Lattaud, J., Kirkels, F., Peterse, F., Freymond, C.V., Eglinton, T.I., Hefter, J., Mollenhauer, G., Balzano, S., Villanueva, L., van der Meer, M.T.J., Hopmans, E.C., Sinninghe Damsté, J.S., Schouten, S., 2018a. Long-chain diols in rivers: distribution and potential biological sources. Biogeosciences 15, 4147-4161. 
Lattaud, J., Kim, J.-H., de Jonge, C., Zell, C., Sinninghe Damsté, J.S., Schouten, S., 2017a. The $\mathrm{C}_{32}$ alkane-1,15-diol as a tracer for riverine input in coastal seas. Geochimica et Cosmochimica Acta 202, 146-158.

Lattaud, J., Lo, L., Huang, J.-J., Chou, Y.-M., Gorbarenko, S.A., Sinninghe Damsté, J.S., Schouten, S., 2018b. A comparison of Late Quaternary organic proxy-based paleotemperature records of the Central Sea of Okhotsk. Paleoceanography and Paleoclimatology 33, 732-744.

Locarnini R.A., Mishonov A.V., Antonov J.I., Boyer T.P., Garcia H.E., Baranova O.K., Zweng, M.M., Paver, C.R., Reagan, J.R., Johnson, D.R., Hamilton, M., Seidov, D., 2013. World Ocean Atlas 2013, Volume 1: temperature. In: Levitus, S and Mishonov, A. (Eds.), NOAA Atlas NESDIS 73, 40 pp.

Lopes dos Santos, R.A., Spooner, M.I., Barrows, T.T., de Deckker, P., Sinninghe Damsté, J.S., Schouten, S., 2013. Comparison of organic $\left(U_{37}^{K \prime}, T E X_{86}^{H}, \mathrm{LDI}\right)$ and faunal proxies (foraminiferal assemblages) for reconstruction of late Quaternary sea surface temperature variability from offshore southeastern Australia. Paleoceanography 28, 377-387.

Marlowe, I.T., Green, J.C., Neal, A.C., Brassell, S.C., Eglinton, G., Course, P.A., 1984. Longchain $\left(n-\mathrm{C}_{37}-\mathrm{C}_{39}\right)$ alkenones in the Prymnesiophyceae.Distribution of alkenones and other lipids and their taxonomic significance. British Phycological Journal 19, 203-216. Méjanelle, L., Sanchez-Gargallo, A., Bentaleb, I., Grimalt, J.O., 2003. Long chain $n$-alkyl diols, hydroxy ketones and sterols in a marine eustigmatophyte, Nannochloropsis gaditana, and in Brachionus plicatilis feeding on the algae. Organic Geochemistry 34, 527-538. 
Müller, P.J., Kirst, G., Ruhland, G., von Storch, I., Rosell-Melé, A., 1998. Calibration of the alkenone paleotemperature index $U_{37}^{K \prime}$ based on core-tops from the eastern South Atlantic and the global ocean $\left(60^{\circ} \mathrm{N}-60^{\circ} \mathrm{S}\right)$. Geochimica et Cosmochimica Acta 62, 1757-1772.

Naafs, B.D.A., Inglis, G.N., Zheng, Y., Amesbury, M.J., Biester, H., Bindler, R., Blewett, J., Burrows, M.A., del Castill Torres, D., Chambers, F.M., Cohen, A.D., Evershed, R.P., Feakins, S.J., Gałka, M., Gallego-Sala, A., Gandois, L., Gray, D.M., Hatchr, P.G., Honorio Coronado, E.N., Hughes, P.D.M., Huguet, A., Könönen, M., Laggoun-Défarge, F., Lähteenoja, O., Lamentowicz, M., Marchant, R., McClymont, E., Pontevedra-Pombal, X., Ponton, C., Poumand, A., Rizzuti, A.M., Rochefort, L., Schellekens, J., de Vleesschouwer, F., Pancost, R.D., 2017. Introducing global peat-specific temperature and pH calibrations based on brGDGT bacterial lipids. Geochimica et Cosmochimica Acta $208,285-301$.

Nürnberg, D., Bijma, J., Hemleben, C., 1996. Assessing the reliability of magnesium in foraminiferal calcite as a proxy for water mass temperatures. Geochimica et Cosmochimica Acta 60, 803-814.

O'Brien, C.L., Robinson, S.A., Pancost, R.D., Sinninghe Damsté, J.S., Schouten, S., Lunt, Alsenz, H., Bornemann, A., Bottini, C., Brassell, S.C., Farnsworth, A., Forster, A., Huber, B.T., Inglis, G.N., Jenkyns, H.C., Linnert, C., Littler, K., Markwick, P., McAnena, A., Mutterlose, J., Naafs, B.D.A., Püttmann, W., Sluijs, A., van Helmond, N.A.G.M., Vellekoop, J., Wagner, T., Wrobel, N.E., 2017. Cretaceous sea-surface temperature evolution: Constraints from $\mathrm{TEX}_{86}$ and planktonic foraminiferal oxygen isotopes. Earth-Science Reviews 172, 224-247. 
Prahl, F.G., Wakeham, S.G., 1987. Calibration of unsaturation patterns in long-chain ketone compositions for palaeotemperature assessment. Nature 330, 367-369.

Rampen, S.W., Schouten, S., Wakeham, S.G., Sinninghe Damsté, J.S., 2007. Seasonal and spatial variation in the sources and fluxes of long chain diols and mid-chain hydroxy methyl alkanoates in the Arabian Sea. Organic Geochemistry 38, 165-179.

Rampen, S.W., Schouten, S., Koning, E., Brummer, G.J.A., Sinninghe Damsté, J.S., 2008. A 90 kyr upwelling record from the northwestern Indian Ocean using a novel long-chain diol index. Annual Review of Earth and Planetary Sciences 276, 207-213.

Rampen, S.W., Schouten, S., Schefuss, E., Sinninghe Damsté, J.S., 2009. Impact of temperature on long chain diol and mid-chain hydroxy methyl alkanoate composition in Proboscia diatoms: Results from culture and field studies. Organic Geochemistry 40, 1124-1131.

Rampen, S.W., Schouten, S., Sinninghe Damsté, J.S., 2011. Occurrence of long chain 1,14-diols in Apedinella radians. Organic Geochemistry 42, 572-574.

Rampen, S.W., Willmott, V., Kim, J.-H., Uliana, E., Mollenhauer, G., Schefuss, E., Sinninghe Damsté, J.S., Schouten, S., 2012. Long chain 1,13-and 1,15-diols as a potential proxy for palaeotemperature reconstruction. Geochimica et Cosmochimica Acta 84, 204-216.

Rampen, S.W., Willmott, V., Kim, J.H., Rodrigo-Gámiz, M., Uliana, E., Mollenhauer, G., Schefuss, E., Sinninghe Damsté, J.S., Schouten, S., 2014a. Evaluation of long chain 1,14alkyl diols in marine sediments as indicators for upwelling and temperature. Organic Geochemistry 76, 39-47.

Rampen, S.W., Datema, M., Rodrigo-Gámiz, M., Schouten, S., Reichart, G.J., Sinninghe Damsté, J.S., 2014b. Sources and proxy potential of long chain alkyl diols in lacustrine environments. Geochimica et Cosmochimica Acta 144, 59-71. 
Rodrigo-Gámiz, M., Martinez-Ruiz, F., Rampen, S., Schouten, S., Sinninghe Damsté, J., 2014. Sea surface temperature variations in the western Mediterranean Sea over the last 20 kyr: A dual- organic proxy ( $U_{37}^{K \prime}$ and LDI) approach. Paleoceanography 29, 87-98.

Rodrigo-Gámiz, M., Rampen, S.W., de Haas, H., Baas, M., Schouten, S., Sinninghe Damsté, J.S., 2015. Constraints on the applicability of the organic temperature proxies $U_{37}^{K \prime}, \mathrm{TEX}_{86}$ and LDI in the subpolar region around Iceland. Biogeosciences 12, 6573-6590.

Schouten, S., Hopmans, E.C., Sinninghe Damsté, J.S., 2013. The organic geochemistry of glycerol dialkyl glycerol tetraether lipids: A review. Organic Geochemistry 54 19-61.

Schouten, S., Hopmans, E.C., Schefuß, E., Sinninghe Damsté, J.S., 2002. Distributional variations in marine crenarchaeotal membrane lipids: a new tool for reconstructing ancient sea water temperatures? Annual Review of Earth and Planetary Science Letters $204,265-274$.

Shackleton, N., 1967. Oxygen isotope analyses and Pleistocene temperatures re-assessed. Nature $215,15$.

Shimokawara, M., Nishimura, M., Matsuda, T., Akiyama, N., Kawai, T., 2010. Bound forms, compositional features, major sources and diagenesis of long chain, alkyl mid-chain diols in Lake Baikal sediments over the past 28,000 years. Organic Geochemistry 41, 753-766. Sinninghe Damsté, J.S., Rampen, S., Rijpstra, W.I.C., Abbas, B., Muyzer, G., Schouten, S., 2003. A diatomaceous origin for long-chain diols and mid-chain hydroxy methyl alkanoates widely occurring in Quaternary marine sediments: Indicators for high-nutrient conditions. Geochimica et Cosmochimica Acta 67, 1339-1348. 
Sinninghe Damsté, J.S., Rijpstra, W.I.C., Hopmans, E.C., Prahl, F.G., Wakeham, S.G., Schouten, S., 2002. Distribution of membrane lipids of planktonic Crenarchaeota in the Arabian Sea. Applied and Environmental Microbiology 68, 2997-3002.

Smith, M., de Deckker, P., Rogers, J., Brocks, J., Hope, J., Schmidt, S., Lopes dos Santos, R., Schouten, S., 2013. Comparison of $U_{37}^{K \prime}, T E X_{86}^{H}$, and LDI temperature proxies for reconstruction of south-east Australian ocean temperatures. Organic Geochemistry 64, 94-104.

ten Haven, H.L., Rullkötter, J., 1991. Preliminary lipid analyses of sediments recovered during leg 117 1., Proceedings of the Ocean Drilling Program, Scientific Results, pp. 561-569.

Tierney, J.E., Tingley, M.P., 2018. BAYSPLINE: A new calibration for the alkenone paleothermometer. Paleoceanography and Paleoclimatology 33 281-301.

Versteegh, G.J.M., Bosch, H.J., de Leeuw, J.W., 1997. Potential palaeoenvironmental information of $\mathrm{C}_{24}$ to $\mathrm{C}_{36}$ mid-chain diols, keto-ols and mid-chain hydroxy fatty acids; a critical review. Organic Geochemistry 27, 1-13.

Versteegh, G.J.M., Jansen, J.H.F., de Leeuw, J.W., Schneider, R.R., 2000. Mid-chain diols and keto-ols in SE Atlantic sediments: A new tool for tracing past sea surface water masses? Geochimica et Cosmochimica Acta 64, 1879-1892.

Villanueva, L., Besseling, M., Rodrigo-Gámiz, M., Rampen, S.W., Verschuren, D., Sinninghe Damsté, J.S., 2014. Potential biological sources of long chain alkyl diols in a lacustrine system. Organic Geochemistry 68, 27-30.

Volkman, J.K., Barrett, S.M., Blackburn, S.I., 1999. Eustigmatophyte microalgae are potential sources of $\mathrm{C}_{29}$ sterols, $\mathrm{C}_{22}-\mathrm{C}_{28}$-alcohols and $\mathrm{C}_{28}-\mathrm{C}_{32}$-alkyl diols in freshwater environments. Organic Geochemistry 30, 307-318. 
Volkman, J.K., Barrett, S.M., Dunstan, G.A., Jeffrey, S.W., 1992. $\mathrm{C}_{30}-\mathrm{C}_{32}$ alkyl diols and unsaturated alcohols in microalgae of the class Eustigmatophyceae. Organic Geochemistry 18, 131-138.

Volkman, J.K., Eglinton, G., Corner, E.D.S., Forsberg, T.E.V., 1980. Long-chain alkenes and alkenones in the marine coccolithophorid Emiliania huxleyi. Phytochemistry 19, 26192622.

Warnock, J.P., Bauersachs, T., Kotthoff, U., Brandt, H.T., Andren, E., 2018. Holocene environmental history of the Angermanalven Estuary, northern Baltic Sea. Boreas 47, 593-608.

Willmott, V., Rampen, S.W., Domack, E., Canals, M., Sinninghe Damsté, J.S., Schouten, S., 2010. Holocene changes in Proboscia diatom productivity in shelf waters of the northwestern Antarctic Peninsula. Antarctic Science 22, 3-10.

Zachos, J., Pagani, M., Sloan, L., Thomas, E., Billups, K., 2001. Trends, rhythms, and aberrations in global climate 65 Ma to present. Science 292, 686-693.

Zweng, M.M., Reagan, J.R., Antonov, J.I., Locarnini, R.A., Mishonov, A.V., Boyer, T.P., Garcia, H.E., Baranova, O.K., Johnson, D.R., Seidov, D., Biddle, M.M., 2013.World Ocean Atlas 2013, Volume 2: Salinity. In: Levitus, S and Mishonov, A. (Eds.), NOAA Atlas NESDIS 74, $39 \mathrm{pp}$. 


\section{Figures}

Fig. 1. Core-top sediment locations investigated in this study. Black circles indicate the surface sediments of Rampen et al. (2012), pink circles indicate surface sediments analyzed for long chain alkyl diols in previous studies (de Bar et al., 2016; Lattaud et al., 2017a,b, 2018; Smith et al., 2013; Rodrigo-Gámiz et al., 2015), and the white circles represent new surface sediment data obtained in this study. The map of sea surface temperatures (SST) is based on data of the World Ocean Atlas (2013) (Locarnini et al., 2013) and made in Ocean Data View (Schlitzer, 2015).

Fig. 2. (a) LDI values of all surface sediments vs annual mean SST (0 m depth; WOA13), and (c) LDI values of marine surface sediments vs annual mean SST when excluding all stations where surface salinity < 32 ppt. The associated excluded sediments belong to the Hudson Bay, Black Sea, Gulf of St. Lawrence, Kara Sea (7 of 8 sediments excluded) and the Baltic Sea (indicated in the legend by strike-through). Panels (b) and (d) show the residual errors associated with the regression of (a) and (c), respectively. In panel (b), the low-salinity core-tops are highlighted which were excluded for the calibration plotted in panel (c). In panel (d), core-tops associated with Proboscia long-chain diol contribution are highlighted, which were excluded from the final LDI-SST calibration (Fig. 6) as discussed in Section 3.2.

Fig. 3. (a) PCA biplot of the long-chain diol proxies, i.e., the LDI and $\mathrm{C}_{32}$ 1,15-diol fractional abundance, and environmental parameters, i.e., annual mean sea surface temperature (AM SST;

${ }^{\circ} \mathrm{C}$ ), salinity, and annual mean phosphate and nitrate concentrations ( $\left.\mu \mathrm{mol} \mathrm{L}^{-1}\right)$; (b)PCA biplot of the fractional abundances of the different long-chain diols. Panel (c) and (e) show the Factor 1 
792 scores of the biplots of panels (a) and (b), respectively, correlated against annual mean SST $\left({ }^{\circ} \mathrm{C}\right)$.

793 Panels (d) and (f) show the Factor 2 scores correlated against the salinity. In cases where the

794 fractional abundance of one or more diols was unknown for a core-top, there was no LDI value,

795 or environmental data (World Ocean Atlas 2013) were not available, this core-top was excluded

796 from the PCA.

797

798

Fig. 4. Selected ion monitoring chromatograms of two sediments (two upper panels) with 'usual'

799 long-chain diol distributions, i.e., with low 1,12-diols. The lower four panels show the

800 chromatograms of four sediments with relatively high $\mathrm{C}_{26}$ and $\mathrm{C}_{28}$ 1,12-diols (blue), as well as

801 the $\mathrm{C}_{27}$ and $\mathrm{C}_{29} 12-\mathrm{OH}$ (green) and $\mathrm{C}_{28}$ and $\mathrm{C}_{30}$ 13-OH methyl alkanoates (brown). These

802 sediments reveal LDI values which deviated substantially from the LDI calibration vs annual

803 mean SST (see Fig. 2). The 'Greenland' sediment is classified as 'North Atlantic Ocean' in Figs.

8042,5 and 6, and the "Pakistan margin" as "Arabian Sea".

805

806

807

Fig. 5. The fractional abundance of the $\mathrm{C}_{28}$ 1,12-diol vs the residual error in SST estimation

based on the regression plotted in Fig. 2c. The black solid lines indicate a fractional abundance

808

of 0.1 , and a residual error of 0 . The dotted lines reflect the negative and positive $2 \times \mathrm{SD}$ value of

$809 \quad 6.8^{\circ} \mathrm{C}$.

810

811 Fig. 6. (a)LDI calibration after exclusion of estuarine sediments (salinity < $32 \mathrm{ppt}$ ), as well as

812 surface sediments in which the fractional abundance of the $\mathrm{C}_{28} 1,12$-diol is $>0.1$. Regions in

813 which surface sediments were excluded based on the $\mathrm{C}_{28}$ 1,12-diol abundance and salinity are

814 indicated by underline and strike-through in the legend, respectively; (b)Residual SST errors 
815 (LDI SST - annual mean SST) against annual mean SST. The black dashed line reflects a

816 residual error of $0{ }^{\circ} \mathrm{C}$, and the grey dashed lines reflect the standard deviation of the residual

817 errors, i.e., the calibration error $\left(3.0^{\circ} \mathrm{C}\right)$.

818

819 Fig. 7. Residual SST errors (LDI SST - measured annual mean SST) plotted on the global map

820 (created in Ocean Data View; Schlitzer, 2015). 